\title{
El lento despegue industrial de Bucaramanga, Colombia (1857-1929)
}

\author{
Álvaro Acevedo Tarazona* \\ Carlos Humberto Espinosa Suárez ${ }^{* *}$
}

Fecha de recepción: 5 de diciembre de 2019

Fecha de aprobación: 10 de enero de 2020

Resumen: Este artículo analiza las condiciones que hicieron posible un incipiente proceso de industrialización en Bucaramanga, Colombia, durante siete décadas, cinco correspondientes al siglo XIX y dos al siglo XX. El origen y monto de los capitales, las profesiones y ocupaciones de los actores económicos, el nivel de riesgo empleado, el sentido de asociación, la conducta empresarial, la tenencia y el uso de la tierra y los diversos sectores de inversión son algunos de los factores que se examinan para comprender por qué la región santandereana no logró consolidar un proceso industrial y comercial similar al experimentado en los departamentos de Antioquia y Valle del Cauca. A partir del concepto de negociante y su desempeño en sectores económicos de producción y comercialización, su vinculación en la industria cultural, la banca, las finanzas y la construcción, se analizarán las políticas y estrategias estatales para incentivar la industrialización en el ámbito nacional con el objetivo de mostrar el avance que hubo en Bucaramanga con referencia a contextos similares. El análisis de archivos notariales y de la prensa local como fuente primaria permite comprender el proceso económico de la región santandereana entre 1857 y 1929; para ello fue fundamental la consulta de protocolos notariales, evidencia de la constitución de empresas y de la transformación de capitales en la región bumanguesa. Este artículo abre una perspectiva para la realización de nuevos estudios que muestren el proceso de desarrollo económico en Santander y descubran las razones de su estancamiento en comparación con otros departamentos colombianos.

Palabras clave: comercio, empresario, fábrica, historia económica, industrialización.

Clasificación JEL: L60, N3, N36, N9, N96.

Cómo citar este artículo/ To reference this article / Comment citer cet article / Para citar este artigo:

Acevedo Tarazona, Á, \& Espinosa Suárez, C. (2020). El lento despegue industrial de Bucaramanga, Colombia (1857-1929). Apuntes del Cenes, 39(69). Págs. 241 - 266 https://doi.org/10.19053/01203053.v39.n69.2020.10429

* Doctor en Historia. Profesor Titular de la Escuela de Historia de la Universidad Industrial de Santander. Bucaramanga - Colombia. Correo electrónico: acetara@uis.edu.co - Contacto de correspondencia. bittp://orcid. org/0000-0002-3563-9213

** Candidato a Doctor en Historia de la Universidad Industrial de Santander. Magíster en Historia. BucaramangaColombia. Correo electrónico: carloshumbertoe@gmail.com https://orcid.org/0000-0002-9067-9795 


\title{
The Slow Industrial Take-Off of Bucaramanga, Colombia (1857-1929)
}

\begin{abstract}
This article analyzes the conditions that made possible an incipient industrialization process in Bucaramanga, Colombia, for seven decades, five corresponding to the 19th century and two to the 20th century. The origin and amount of capital, the professions and occupations of economic actors, the level of risk used, the sense of association, business conduct, ownership and use of land and the various investment sectors are some of the factors examined to understand why the Santander region failed to consolidate an industrial and commercial process similar to that experienced in the states of Antioquia and Valle del Cauca. Based on the concept of the merchant and its performance in economic sectors of production and marketing, its link in the cultural industry, banking, finance and construction, state policies and strategies to encourage industrialization at national level will be analyzed with the objective to show the progress made in Bucaramanga with reference to similar contexts. The analysis of notarial archives and of the local press as a primary source make possible to understand the economic process of Santander region between 1857 and 1929; for this, the consultation of notarial protocols, evidence of the constitution of companies and the transformation of capitals in Bucaramanga region was essential. This article opens a perspective for the realization of new studies that show the process of economic development in Santander and find out the reasons for its stagnation compared to other Colombian departments.
\end{abstract}

Keywords: trade, entrepreneur, factory, economic history, industrialization. 


\section{INTRODUCCIÓN}

El objetivo de este artículo es presentar un acercamiento a la historia empresarial del departamento de Santander, a partir del análisis de la inversión y el comportamiento de los actores económicos. La pregunta que orienta este artículo es por qué los negociantes bumangueses, si tuvieron una experiencia comercial después de la segunda mitad del siglo XIX, no tomaron ventaja de esta situación para dar el salto hacia una industrialización completa. Se trata de un proceso que ha sido escasamente estudiado en la región oriental de Colombia, lo cual contrasta con los análisis existentes para la región antioqueña y del Valle del Cauca.

Para elaborar este artículo se consultaron textos escritos por expertos en historia empresarial colombiana, como Carlos Dávila (1986), Adolfo Meisel (2015), José Antonio Ocampo (1984), Juan Echavarría (1999) y Susana Valdivieso (1991), quienes han realizado investigaciones acerca del proceso de industrialización. Sus trabajos son muy ilustrativos porque muestran la evolución de la economía colombiana y ayudan a comprender la formación del artesanado, la permanencia de la manufactura y la organización de las primeras fábricas en el siglo XIX y su posterior evolución, lo que contribuye a explicar el desarrollo de la economía bumanguesa durante las tres primeras décadas del siglo XX.

La historiografía consultada se apoya en fuentes primarias compuestas por documentos notariales, especialmente los relacionados con la constitución de sociedades comerciales; también se revisaron los periódicos locales como La Vanguardia Liberal y El Deber, revistas de clubes sociales como El Campestre y de entidades como la Sociedad de Mejoras Públicas. Esta información permitió identificar quiénes invertían, en cuáles sectores, el monto de los capitales, así como el impacto de estas inversiones en el comercio, la industria y la empresa en Bucaramanga durante el periodo referenciado. También se consultaron algunas crónicas de empresarios y funcionarios adscritos a la Secretaría de Hacienda del municipio de Bucaramanga. 
El artículo se organiza de la siguiente forma: el primer apartado hace énfasis en el desarrollo y la consolidación de la vocación comercial, y el surgimiento de los comerciantes en la ciudad de Bucaramanga. Partiendo de esta premisa se pudo analizar su transformación en negociantes y empresarios, en lo que se considera el despertar industrial de la ciudad. Paralelamente se estudió la problemática del lento despegue de la industrialización durante los primeros treinta años del siglo XX y se finaliza con una exposición de los sectores privilegiados por la inversión de capital.

\section{LA VOCACIÓN COMERCIAL Y LA CONSOLIDACIÓN DEL CO- MERCIANTE BUMANGUÉS}

En 1622 Bucaramanga fue fundada como un pueblo de indios por parte de la Corona española, una condición de menor jerarquía que no le permitió configurar el trazado de damero, propio de las villas y ciudades del Nuevo Mundo, ni mantener autonomía política ni administrativa como sí la tuvo la población colindante de San Juan de Girón. Casi siglo y medio después de organizado, el asentamiento alcanzó el estatus de parroquia en 1778, y en 1795 el doctor Nicolás de Rojas hizo el trazado de las manzanas partiendo de lo que era la plaza principal hacia el oriente, lo que derivó en una tendencia de crecimiento y urbanización hacia ese punto cardinal y en el que posteriormente se ubicó el eje comercial de la ciudad.

Durante el periodo posindependentista, Bucaramanga no obtuvo reconocimiento nacional administrativo, político o económico, pues el liderazgo lo tenían las poblaciones de Socorro y Girón. Con la creación del Estado Soberano de Santander el 13 de mayo de 1857, y Bucaramanga como capital, esta adquirió importancia regional y personas de diversos lugares se asentaron en la ciudad, lo que conllevó el crecimiento poblacional y urbanístico y un flujo comercial alto. Durante los años 70 del siglo XIX se presentó una "inmigración alemana", que estuvo conformada por un grupo de hombres solteros, jóvenes, con capital donado por el Imperio y con un fuerte espíritu empresarial (Rodríguez, 1968, pp. 1113), que revitalizó el comercio local y regional y fortaleció el internacional poniendo a Bucaramanga en contacto con los puertos más importantes de la época, como Hamburgo y Bremen ${ }^{1}$ en Alemania, y Nueva York en Estados Unidos. Esta inmigración estuvo conformada por 23 personas (Censo del Departamento de Santander, 1896, p. 16); un número pequeño en comparación con Canadá, Australia, Argentina y Estados Unidos, que tuvieron un proceso similar. No obstante, este escaso número logró enorme influencia social, gracias a los enlaces matrimoniales

1 Bremen fue el principal destino tabacalero de Europa durante la segunda mitad del siglo XIX, cuando Java, Sumatra y las Indias Holandesas rebajaron el precio, pero factores como la calidad, la producción, el procesamiento y el empaque no eran los mejores y llevaron a la crisis del tabaco colombiano. 
con la élite local. Y la unión de las fortunas posibilitó organizar casas de importación y exportación, las cuales les otorgaron dividendos económicos y prestancia social e incluso participación en la planeación de la ciudad. A la par del comercio internacional, estos extranjeros ejercieron funciones diplomáticas; por ejemplo, el Consulado de Alemania fue encargado a Paul G. Laurent, sobrino del alemán Geo Von Lengerke; el de Venezuela a Manuel Cortissoz, el de España a José Joaquín García, y el de Francia a Víctor Paillié.

Esta fusión de capitales, el aprovechamiento de contactos en el exterior y la experiencia en los negocios se materializaron en las "sociedades mercantiles" o "de comercio" que se ubicaron en la "Calle del Primer Chorro", luego denominada "Calle del Comercio" -hoy calle 35 de la ciudad de Bucaramanga- debido a la profusión de establecimientos como tiendas, casitiendas y almacenes. Estos establecimientos se diferenciaban por el espacio disponible, la ubicación en el plano de la ciudad y los productos que expendían. En este contexto, las tiendas y almacenes contaban con mayor amplitud que las casitiendas, porque ofrecían una amplia gama de productos, mientras que las segundas vendían productos de primera necesidad de la época, como pan, jabón, velas, etc. En el plano de la ciudad, las tiendas y almacenes más grandes y prestigiosos se ubicaron en la Calle del Comercio, mientras que las casitiendas estaban localizadas en las afueras, especialmente en las vías de acceso, lo cual favoreció a los sectores campesinos. Además, las tiendas y casitiendas ofrecían productos necesarios o de venta en el mercado dominical, mientras que los productos de los almacenes iban dirigidos a la clase pudiente y algunos ofertaban medicinas para la curación de las enfermedades tropicales (Periódico El Posta, 1895, p. 7).

Teniendo en cuenta que el flujo comercial era de doble vía, generalmente los importadores también eran exportadores, y despachaban cueros de res y cabra, frutos de la tierra, añil, quina (Ocampo, 1984 p. 293), sombreros de jipijapa (Martínez, 2005, p. 51)² y café, e importaban vestuario, zapatos, loza, mobiliario, vinos, etc. En el almacén de Silva Otero Hermanos se podía adquirir vestuario elaborado en afamadas fábricas alemanas, en el almacén de Francisco A. Barreto se vendían "géneros de seda, lana y algodón, guantes de seda y piel de Suecia, pañolones y abrigos" (Periódico El Posta, 1893, p. 3). En algunos casos, los productos importados se mezclaban con los nacionales; por ejemplo, en la casa comercial de Trinidad Parra de Orozco \& Cía. se expendían mercancías

2 A estos sombreros se les llamó Panamá o Panamás y se desconoce el origen de esta denominación. Estos accesorios eran producidos y comercializados en los vecinos municipios de Girón y Lebrija, luego traídos a Bucaramanga y posteriormente enviados a Las Antillas o al sur de Estados Unidos para ser usados en las plantaciones de caña de azúcar. En Colombia su elaboración fue notoria en Santander, Huila y Antioquia, y su apogeo se dio hacia 1850; una década después empezó su decadencia por la calidad y el mercado fue tomado por los cubanos (Ocampo, 1984, p. 184). 
inglesas, francesas y estadounidenses, como "cortes de algodón, adornos para sala, driles, encajes, parches porosos allcocks, vestidos, ropa interior, flores artificiales, agua florida legítima de Murray \& Lanman, máquinas de coser, vino tinto, blanco, Vermouth, Oporto y Málaga imperial", que se mezclaban con artículos típicos como "ruanas de paño y de merino, las gamuzas y las pieles de marrano" (Carreño, 2015, p. 106).

Generalmente, los productos eran importados de Europa o Estados Unidos por intermedio de las casas comerciales; luego eran dejados en algunas islas del Caribe para ser llevados a los puertos de Santa Marta, Cartagena y Barranquilla. Posteriormente eran despachados por el río Magdalena hacia los muelles fluviales de Puerto Botijas, Bodega Central y Bodega del Sogamoso, donde eran depositados para ser transportados por el río Lebrija hasta Rionegro, en Santander, y finalmente llegaban a Bucaramanga a lomo de mula para ser puestos y ofertados en los almacenes de la Calle del Comercio 3 (Carreño, 2015, p. 93). Pero si el comercio interregional era difícil, lo era aún más el comercio exterior; así que para salvar estas dificultades, la propuesta de los gobernantes fue enlazar las regiones mediante los ferrocarriles y conectarlas con el río Magdalena que era la vía hacia el exterior (Ocampo, 1984, p. 144), proyecto que simultáneamente mejoraría las conexiones interregionales, pero al final no tuvo el éxito esperado debido a la demora en su construcción (Correa, 2011, p. 52).

Esta actividad comercial también derivó en la modificación arquitectónica de la ciudad y en el uso del suelo, porque se hizo habitual construir viviendas de dos pisos: el primero para el comercio y el segundo para vivienda. Además, se habilitaron espacios dedicados al esparcimiento como el Liceo de Soto (1872), que luego se denominó Club de Soto (1873) y posteriormente Club del Comercio (1877), cuyo objetivo era servir de espacio de relación social a los comerciantes adinerados. De las conversaciones en este club, y apoyados en la política de la banca libre, surgió la idea de organizar una entidad crediticia para agilizar las transacciones comerciales con el exterior. Esta propuesta se materializó en la apertura de los bancos de Santander (1872) ${ }^{4}$ (Archivo Notaría Primera de Bucaramanga [ANPB], 1872) y Prendario de Soto (1873) (ANPB, 1884), los cuales tuvieron una vida efímera debido a la inestabilidad política y económica generada por las guerras civiles.

3 Mientras se hacía la declaración de importación, las mercancías eran guardadas en las bodegas de la aduana, donde se podían dañar o perder porque los espacios eran muy reducidos y generalmente estaban en pésimas condiciones. Cuando la bodega estaba llena o cerrada y no se podían almacenar, los productos eran entrados en forma ilegal para no pagar impuestos y eran comercializados en las ferias o vendidos en forma clandestina (Laurent, 2008, pp. 380-432).

4 Esta entidad financiera fue organizada en 1872, pero empezó a funcionar el 18 de agosto de 1873 (Espinosa, 2017, pp. 96-97). 
En cuanto a la cuestión ocupacional, el comercio fue otra opción de empleo, como lo muestra el censo de población de 1871 con 250 comerciantes, discriminados en 235 hombres y 15 mujeres (Censo del Estado Soberano de Santander, 1871); cifra que se incrementó a 726 con 631 hombres y 95 mujeres en 1896 (Censo de Población del Departamento de Santander. 1896, p. 15). Como se puede observar, el número estuvo en constante aumento, lo que contribuyó a consolidar la tipología del comerciante como aquella persona dedicada a especular con cualquier actividad que le generara dividendos, los cuales eran reinvertidos en la misma sociedad comercial o en otra que estuviera en boga, tendencia que se replicaba en buena parte del país, aunque también se presentaron algunos casos de transición exitosa hacia la industrialización, especialmente en el departamento del Valle del Cauca con los ingenios azucareros (Arroyo, 2006, p. 45) y la vinculación de la tierra a la agroindustria, lo que, a su vez, asume un cambio de comerciante a hacendado y posteriormente a industriales como Santiago M. Eder, quien de asesor comercial en importaciones $\mathrm{y}$ exportaciones en Buenaventura, se convertiría en el empresario y propietario de una de las empresas colombianas más reconocidas: Ingenio Manuelita, empresa pionera en la agroindustria colombiana.

Otro impacto del comercio se manifestó en el prestigio nacional e internacional que Bucaramanga empezó a tener cuan- do se convirtió en lugar preferencial para el establecimiento de sucursales y agencias. En consecuencia, llegaron firmas comerciales de Bogotá, Colón, Ocaña y Rionegro, y algunas provenientes de Alemania y Estados Unidos, con lo cual se amplió la oferta comercial de la ciudad y la región (Guerrero \& Avellaneda,2003, pp. 25-43).

Este dinamismo comercial se entremezcló con ciclos económicos de exportación de productos nacionales como el tabaco, la quina y el café. El primero de ellos fue tan importante que hasta mediados del siglo XIX su monopolio representó para el país el $50 \%$ de la producción, luego perdió importancia y la recuperó entre 1850 y 1875; en 1890 tuvo un descenso y después empezó un lento posicionamiento (Acevedo \& Torres, 2016, p. 297).

Bucaramanga también participó en la denominada "fiebre de las quinas" cuando se descubrió en sus alrededores la especie denominada "cúprea", que por su calidad fue apetecida en los mercados europeos. El posicionamiento de este producto se hizo por intermedio de la casa comercial del alemán Paul G. Lorent en dos periodos: $1867-1873$ y $1877-$ 1882. Estos ciclos económicos trajeron una frágil prosperidad a la ciudad, que terminó cuando en Asia se descubrió una especie de superior calidad cuyo transporte era más ágil y económico. En consecuencia, los pedidos de quina fueron suspendidos, las inversiones en tierras y los jornales descendieron os- 
tensiblemente y ocasionaron un fuerte daño a la economía local.

Sin embargo, esta crisis económica fue superada cuando el café se posicionó en los mercados internacionales y para 1880 representaba el $50 \%$ de las exportaciones del país (Ocampo, 1984, p. 293). Bucaramanga y Santander participaron activamente en este nuevo renglón de exportación hasta el inicio de la guerra de los Mil Días. Aunque este renglón fue destacado en la economía regional, para autores como Juan Echavarría, la actividad más lucrativa en el país era el comercio exterior y no el café, en atención a que fue un sector de inversión, pero no un generador de riqueza, como fue la tendencia en Antioquia (Echavarría, 1999, p. 96).

Para finalizar, Bucaramanga acentuó su vocación comercial durante la segunda mitad del siglo XIX, vocación que, vista en el contexto nacional, fue tardía porque ciudades como Bogotá y algunas de la Costa Atlántica tenían un activo comercio con Las Antillas y Europa desde la época posindependentista (Molina, 2006, p. 241). En líneas generales, este dinamismo comercial condujo a la consolidación de la tipología de comerciante y a la acumulación de capitales, algunos de los cuales se esfumaron durante la guerra de los Mil Días, otros permanecieron estáticos en manos de descendientes $\mathrm{y}$, finalmente, algunos se utilizaron para la industrialización de la ciudad. En el caso bumangués, el comercio sirvió como experiencia para sentar las bases fabriles y empresariales durante las tres primeras décadas del siglo $\mathrm{XX}$.

\section{EL DESPERTAR DEL SIGLO XX: ENTRE NEGOCIANTES, FÁBRI- CAS Y FABRIQUINES}

Las nueve guerras civiles (Giraldo, Fortou \& Gómez, 2019, p. 360) que azotaron el territorio nacional durante el siglo XIX estuvieron acompañadas de levantamientos, amotinamientos y cuartelazos, y afectaron la producción cafetera, promovieron la huida y muerte de trabajadores, con la consiguiente disminución de la mano de obra. Estas guerras civiles ocurridas entre 1839 y 1902 estuvieron enmarcadas por conflictos políticos (guerra de los Supremos, guerra de los Mil Días) y algunas por diferencias políticas con un trasfondo económico (guerra de los Artesanos). Lo cierto es que estos conflictos frenaron el desarrollo económico del país durante buena parte del siglo XIX. Esta situación pudo haber atemperado el espíritu empresarial santandereano que se estaba incubando y posteriormente se manifestaría en la aversión al riesgo cuando los negociantes buscaron diversos sectores de inversión como una forma de proteger el patrimonio, lo cual derivaría en proyectos empresariales pequeños y con avances muy lentos. En este panorama hubo propuestas estatales como la banca libre y el intento de una banca central que se materializó con la apertura del Banco Nacional. Finalmente estalló la guerra de los Mil 
Días (1899-1902), que llevó a la nación a un descalabro económico palpable en lo que se considera la inflación más alta en la historia nacional, la cual alcanzó entre los años 1900 y 1903 cifras de $38 \%$, $187 \%$, 318\% y $169 \%$ respectivamente (Meisel, 2015, p. 8).

Además, como consecuencia de la guerra, se abandonaron las haciendas cafeteras, especialmente en Cundinamarca y Santander, lo cual condujo al descenso de la producción hasta en un $80 \%$, y la crisis se agravó con la caída de los precios internacionales del grano (Ocampo, 1984, pp. 195-196), y como el café era la base de la economía, se afectó el tesoro nacional, y en el ámbito internacional la desconfianza de la inversión extranjera aumentó. Los efectos de la guerra también se apreciaron en la interrupción en la construcción de las carreteras y los ferrocarriles, fundamentales para el despegue económico. En el caso santandereano, el auge del café y el establecimiento de Cúcuta como centro de acopio de este producto, llevaron a la pretensión de construir un ferrocarril que partiera de Cúcuta y cuyo recorrido terminara en el departamento de Santander (Olarte, 2006, p. 15). Este anhelo sería interrumpido por la guerra de los Mil Días, época en la cual la baja en los precios del café dio al traste con la prosperidad económica de la región; por consiguiente, la puesta en marcha del ferrocarril del Táchira en 1896 solo sería viable hasta 1926 cuando se hizo el empalme con el ferrocarril de Cúcuta (Pradilla, 2012, p. 89).

Cuando el presidente Rafael Reyes (1904-1909) asumió el poder, el déficit era de 6500000 pesos de la época (Cruz, 1964, p. 1781), una suma bastante alta para cubrir, si se tienen en cuenta las difíciles condiciones económicas. Considerando lo anterior, las políticas se centraron en la recuperación económica, por eso el mandatario "otorgó exenciones generales y particulares para la importación de materias primas, el establecimiento de subsidios y creó un sistema proteccionista más operativo y eficaz cuyo objetivo era balancear las importaciones y las exportaciones que la guerra había desequilibrado y presentó estímulos al amparo de los cuales empezó a consolidarse el andamiaje industrial del país" (Ocampo, 1984, p. 198). El objetivo era balancear las importaciones y las exportaciones que la guerra había desequilibrado. Estas políticas se reforzaron con la creación en 1905 del Ministerio de Obras Públicas y Transporte, cuyo fin era modernizar y acelerar la construcción de vías para dinamizar el comercio regional y mejorar la competitividad internacional que se veía afectada por los altos costos de los fletes y los seguros, las peripecias para el transporte de productos perecederos por trochas y caminos, por el tiempo que transcurría entre el pedido y la entrega, y los deterioros del producto. Como era una problemática

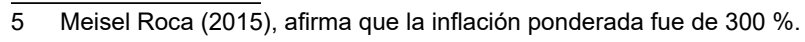


nacional, se trató de superar mediante la construcción de ferrocarriles desde 1870, con el agravante de que en Santander la construcción de la línea de Puerto Wilches duró aproximadamente 70 años, mientras que en otras regiones la conexión fue rápida y temprana (Guerrero, Acevedo \& Fuentes, 2014, pp. 82-83), lo cual se tradujo en una desafortunada diferencia económica para las diversas regiones colombianas. Otra decisión del presidente Reyes fue promover una convivencia pacífica entre liberales y conservadores a través del republicanismo para aminorar los enfrentamientos partidistas, decisión que dio como resultado un periodo de paz que se extendió durante las primeras tres décadas del siglo XX y redundó en el aumento de las inversiones (El Deber, 1931, p. 2).

Un acercamiento al proceso de industrialización en la ciudad incluye la revisión del papel de los capitales, la educación de los actores económicos, la conducta empresarial que involucra el riesgo y la asociación, y como último factor, la innovación tecnológica. Con referencia al primero, los capitales que sobrevivieron a la guerra de los Mil Días fueron muy pocos y entre los que merecen citarse, dado su monto, están los de Reyes González Hermanos y Trinidad Parra de Orozco. En el primer caso, Reyes González empezó su vida comercial con la compraventa de inmuebles urbanos y rurales en el vecino municipio de Matanza; posteriormente ocupó puestos administrativos y se dedicó a los remates de degüello y aguardiente, abrió la sociedad "Reyes González Hermanos" y participó en la planeación de Bucaramanga con obras como la Plaza de Mercado Cubierto y la adecuación del parque Reyes González que dinamizó la urbanización del sector nororiental. Este negociante fue estudiado por David Johnson, quien analizó las transacciones efectuadas en Bucaramanga durante los años de 1885$1887,1890,1894-1895$ y $1899-1900$, y llegó a la conclusión de que entre los principales compradores de finca raíz registrados en las Notarías Primera y Segunda de Bucaramanga estaban la sociedad mercantil Reyes González Hermanos con 54 transacciones por valor de 195238 pesos de la época, seguida por Minlos Breuer \& Cía. con 176635 pesos y diez transacciones, y en tercer lugar Bernabé Rey con seis transacciones y 66600 pesos (Johnson, 1989, p. 39). El caso de Trinidad Parra de Orozco es diferente, porque heredó cierta fortuna de su padre, Juan Crisóstomo Parra, que reprodujo a través de la sociedad comercial que organizó en compañía de su esposo Nicolás Genaro Orozco, hasta convertirse en la mujer más rica de la ciudad durante la segunda mitad del siglo XIX; cuando falleció, en 1898, la herencia se repartió entre sus descendientes. El aspecto para enfatizar es que no hubo un tejido familiar que permitiera la continuidad de las sociedades o, en el mejor de los casos, liquidarlas y organizar otras en los sectores de inversión que fueran surgiendo. Esta disgregación de capitales influyó en la industrialización de la región debido a que las propiedades y las fortunas se estancaron en manos familiares y en 
otras oportunidades migraron o simplemente desaparecieron.

En el mismo sentido, Susana Valdivieso (1991) plantea que de mil personas que declararon renta en 1896 por tener una fortuna superior a cien pesos, setenta y dos poseían más de diez mil pesos y otras tenían más de ochenta mil pesos, como David Puyana, Reyes González y Nepomuceno Cadena, que, a juicio de la autora, serían los grupos rectores de la economía local (Valdivieso, 1991, p. 14). Teniendo en cuenta las sociedades comerciales que se abrieron a comienzos del siglo $\mathrm{XX}$, ninguno de los comerciantes mencionados lideró algún renglón. Por ejemplo, Reyes González, quien fue el empresario más importante de fines del siglo XIX, realizó la última transacción en 1903, luego se enfermó y falleció en 1905. Cuando la sociedad se liquidó en 1903, el capital era de 8210 303 en papel moneda; la sociedad se reorganizó con cinco millones de pesos o cincuenta mil pesos oro (Johnson, 1989, p. 37). Por consiguiente, esta fortuna no entró a dinamizar la economía local, pese a ser la más grande del momento. En el caso de Trinidad Parra de Orozco, el juicio de sucesión no arroja mayor información sobre la herencia. Otra de las fortunas fue la de David Puyana, quien falleció en 1909 y, a diferencia de los anteriores, sus herederos trataron de conservar y reproducir el capital en el ramo de la construcción a través de la firma Sucesores de David Puyana S.A. que, en compañía de otras sociedades, urbanizó buena parte de la ciudad durante el siglo $\mathrm{XX}$.

Otro de los capitales que se usó para la industrialización de la ciudad fue el de Tobías Valenzuela, quien originalmente se dedicó al comercio, luego su prestancia social lo llevó a ser el primer presidente del Club de Soto (1873) -hoy Club del Comercio-y participó en la organización del Banco de Santander (1873). Posteriormente se asoció con sus hijos, con Alfonso Silva Silva y la sociedad Alfredo \& Ambrosio Peña e introdujo el automóvil Citroën en la ciudad (1926); además participó en la Empresa de Transportes Terrestres y el Gimnasio Santander. En 1928, en compañía de Miguel Valenzuela, conformó la Empresa de Urbanizaciones, y en 1929 formó parte de la Unión Cigarrera de Santander, que exportaba cigarrillos a los departamentos de Antioquia, Bolívar, Caldas, Magdalena y Valle del Cauca (Vanguardia Liberal, 1929, p. 5).

Si se comparan los capitales bumangueses con los antioqueños, los últimos eran más grandes teniendo en cuenta que no solo se originaron en el comercio, sino también surgieron de la minería de oro que estuvo presente desde la época colonial, lo cual permitió la acumulación durante varias generaciones, hasta el punto de que durante las guerras civiles del siglo XIX algunos antioqueños actuaron como prestamistas del Estado, y figuras como Pepe Sierra y Carlos Coriolano Amador eran catalogados como 
millonarios y gozaban de prestancia nacional (Molina, 2006), mientras que los negociantes bumangueses solo tuvieron prestancia local y en los inicios del siglo XX no fueron más allá del tímido mercado regional.

Otros ejemplos se pueden encontrar en el Valle del Cauca y Barranquilla, que tomaron el liderazgo nacional en la producción de azúcar refinada, lo cual implicó que el monto de los capitales fuese bastante alto y permitió la puesta en funcionamiento de los ingenios azucareros de Manuelita y Sincerín (Rippol, 1997, p. 73). Por su parte, Bogotá tuvo el liderazgo nacional hasta cierto momento y los capitales empleados fueron aportados por "hacendados, grandes comerciantes, banqueros, rentistas y empleados que ocuparon altos cargos en el Estado [...] quienes a través del comercio exterior (exportación de tabaco y especialmente café e importaciones de bienes en su mayoría de consumo) acumularon cierto capital" (Berdugo, 2019, p. 117).

La permanencia de algunos capitales permitió que en plena guerra de los Mil Días se abrieran sociedades comerciales como la Tipografía Mercantil de Andrés C. Nigrinis, Francisco Vargas \& Hnos., que aún funcionaba en 1944; la Droguería Cadena, la sociedad Penagos Hermanos, que seguía vigente a mediados del siglo XX; A. Aljuri \& Hno., dedicados al comercio de importación y exportación; Chalela Hermanos, que fungían como comerciantes y comisionistas;
Pastas La Italiana de Quintilio Gavassa Mibelli; Droguería del Comercio, Lega Hermanos y Barbour Hermanos, que eran importadores y exportadores a Estados Unidos y Europa; las fábricas de cigarros y cigarrillos La Hamburguesa de Pedro Sepúlveda, La Sin Rival de Ramón Vergel, La Habana de Villamizar Hermanos, y Pedro E. Novoa, dedicado al comercio y las comisiones.

El segundo aspecto para analizar es el nivel educativo de los socios, el cual se puede verificar en los protocolos de las sociedades comerciales de las Notarías Primera y Segunda de Bucaramanga, en los que fueron consignadas las diferentes profesiones y ocupaciones. Para ejemplificar se tomaron aleatoriamente tres sociedades: el Banco de Santander (1914) (ANPB, 1914), que tuvo once socios, siete eran comerciantes, dos agricultores, un abogado y un médico; la segunda fue la Compañía Empresaria de Puerto Wilches (1915) (ANPB, 1915) con quince socios, entre los que había once comerciantes, dos hacendados, un abogado y un médico, y la tercera, el Club Campestre (1930) (ANPB, 1930), que fue concebido como un sitio de esparcimiento y tenía catorce socios, diez de ellos comerciantes, dos ingenieros, un abogado y un médico. Aunque no todos los protocolos dan cuenta de la ocupación de los intervinientes, la mayoría eran "comerciantes" y se desconoce el nivel educativo. En departamentos como Antioquia se vio la necesidad de formar ingenieros, por eso se abrió la Escuela de Minas de Medellín en 1886 
(Martínez, 2013, p. 57), que luego cambió a Escuela Nacional de Minas (1887) en atención a que Antioquia era el departamento minero del país y, finalmente, en 1906 se anexó a la Universidad de Antioquia. En este contexto, algunos de sus egresados ocuparon empleos en el sector público jalonando así el proceso de industrialización; en otras ocasiones los negociantes antioqueños enviaron a sus hijos al exterior, para que al regreso dirigieran las empresas de forma tecnificada y bajo parámetros de administración moderna (Sáenz, 2007, p. 27) ${ }^{6}$.

Considerando que la educación podía generar desarrollo y sacar al país del atasco económico y tecnológico en el que se encontraba, se abrió en Bogotá la Universidad Nacional de los Estados Unidos de Colombia (1867) para formar ingenieros. La diferencia con Antioquia radicó en que había estudiantes de diversas regiones del país y no pretendió estructurar una clase dirigente $o$ empresarial. En Bucaramanga no hubo instituciones técnicas o tecnológicas modernas que formaran los futuros técnicos o ingenieros que industrializaran la región (Ocampo, 1984, p. 144). La primera institución de este corte fue la Escuela de Artes y Oficios (1888), la cual tuvo como objetivo capacitar a los jóvenes de la época en oficios manuales para acceder a un empleo cualificado, pero se estancó durante la primera mitad del siglo XX y solo desde 1948 Bucaramanga y el oriente colombiano contaron con una institución de educación superior, la Universidad Industrial de Santander, que tenía como objetivo industrializar la región. Al momento de la apertura de esta Universidad, en Bogotá y Antioquia ya habían egresado varias generaciones de profesionales que influyeron en el desarrollo regional.

Desde el punto de vista conceptual, la historia empresarial colombiana maneja el término "comerciante" para el siglo XIX, porque hubo dedicación exclusiva a esta actividad, ya fuese local o internacional. Para el periodo de la hegemonía conservadora (1886-1930), Carlos Dávila Ladrón de Guevara propone el concepto de "negociante", porque los actores económicos invirtieron los excedentes en cualquier actividad que les produjese alguna ganancia como una forma para proteger el patrimonio. El autor sostiene que los negociantes respondieron al "patrón de alta diversificación económica que identificó a la mayoría de los individuos de la época ante las condiciones de incertidumbre en el país" (Dávila, 1986, pp. 12-31)7,

6 Aunque no fue una constante, un ejemplo fue Mariano Ospina Pérez, sobrino de Pedro Nel Ospina, fundador de la Escuela de Minas de Antioquia, institución de la cual Mariano se graduó en 1912. Posteriormente hizo un posgrado en la Universidad de Lousiana y al regreso supervisó los negocios familiares de café, fue rector de la Escuela de Minas, senador y ministro de Obras Públicas durante el Gobierno de su tío Pedro Nel. En 1929 fundó la Federación Nacional de Cafeteros para defender los intereses del gremio y finalmente fue elegido presidente de la República para el periodo 1946-1950.

7 A esta propuesta conceptual se adhiere Susana Valdivieso, quien los denomina "negociantes de oportunidad", debido a que los nombres se repetían en las diversas sociedades mercantiles porque la inversión iba acorde con los productos o negocios que fueran surgiendo; no obstante, la autora no lo desarrolla conceptualmente (Valdivieso, 1991, pp. 18-19). 
la cual fue generada por las guerras y el desorden fiscal del Estado. Por consiguiente, el negociante recurrió a multiplicidad de inversiones como "el comercio de exportación e importación, agricultura, finanzas, ganadería, transportes, finca raíz, industria, concesiones estatales y activa participación en política" (Dávila, 1986, p. 12). Con respecto a esta tipología, Dávila identifica algunos comportamientos como el desinterés por la modernización tecnológica y la industria mecanizada, el apego a la especulación, el deseo de enriquecimiento rápido y la inclinación por el bajo riesgo. Estos comportamientos lo diferencian del empresario e industrial, que se caracteriza por la innovación tecnológica, el alto riesgo de las inversiones, el emprendimiento y la expansión comercial. Como esta es una tipología que se repite en varias regiones del país, el autor plantea que "no son empresarios ni industriales, tampoco comerciantes [...] Son entonces negociantes, sus negocios varían desde la usura hasta la fundación de industrias manufactureras" (Dávila, 1986, p. 12).

Atendiendo a la tipología del negociante, es válido señalar que en la Bucaramanga de los tres primeros decenios del siglo XX hubo una gran cantidad de individuos que originalmente se dedicaron al comercio y posteriormente invirtieron capital y excedentes en diversos renglones económicos según su concurrencia. Una explicación a este comportamiento remite a la vocación comercial en la ciudad y a la producción cafetera en sus alrededores, actividades que solo demandaban la compraventa de mercancías nacionales e importadas, pero no producirlas, y en el caso del café, el hacendado se dedicaba a esperar pacientemente las cosechas para el aprovechamiento y comercialización del mismo, y en este ciclo productivo la inversión tecnológica era escasa o nula. Por el contrario, en regiones como Antioquia, la acumulación de capitales se basó en el comercio y la extracción del oro, la cual demandó inversiones en maquinaria y tecnología importada o fabricada en los municipios cercanos. Estas circunstancias hicieron que "la actividad minera contribuyera a moldear algunos rasgos del espíritu empresarial antioqueño, a familiarizarlos con formas relativamente complejas de sociedades, a enfrentarlos a inversiones a largo plazo y a ponerlos en contacto con la tecnología extranjera" (Ocampo, 1984, p. 80). En este orden de ideas, el negociante antioqueño amplió su sociedad mercantil, se volvió empresario y expandió el mercado local y regional, mientras que en Santander, como hubo prevalencia de minifundios y haciendas cafeteras, los propietarios no vieron la innovación tecnológica como una necesidad o una inversión, sino como un gasto innecesario que no estaban dispuestos a asumir, y es posible que este escenario llevase a cierto conformismo y bajo riesgo en las inversiones.

Otra característica del proceso de industrialización bumangués fue que las factorías convivieron con una figura 
económica con poco arraigo en el país, los fabriquines, en los que se elaboraban manualmente cigarros, alpargatas y sombreros de nacuma, sastrería y carpintería, trabajo en oro y plata, velas y curtiembres (Valdivieso, 1991, p. 17). De estas unidades de producción hay dos referencias en las fuentes consultadas, una de 1940 en la revista de la Cámara de Comercio de Bucaramanga y otra de 1947; en esta última, Mario Galán Gómez afirmaba que había fabriquines en Socorro, Zapatoca, Piedecuesta, Málaga y especialmente en Bucaramanga, y calculaba el número en 483 , los cuales producían el ciento por ciento de los cigarros de tercera clase que exportaba el departamento y gran parte de los cigarros de segunda; allí, los obreros laboraban bajo condiciones bastante desventajosas: recibían la materia prima de las fábricas y el salario dependía de la labor realizada, lo cual hacía que "el estándar de vida fuera muy estrecho y casi siempre de miseria" (Galán, 1947, pp. 328-329). Sumado a lo anterior, la escasa experticia en la elaboración de los cigarros se conjugaba con hojas de mala calidad, lo cual terminaba en un producto que era rechazado por las fábricas y en ocasiones desechado; situación que significaba pérdidas para las dos partes, especialmente para las obreras, por cuanto no percibían ninguna remuneración.

En este contexto, la inserción tecnológica se redujo a algunas fábricas, especialmente de cigarros y cigarrillos como las de Villamizar Hermanos, La
Hamburguesa, la cual operaba con tecnología traída desde Cincinnati (Libro Azul de Colombia, 1918, p. 592), y la Compañía Harinera de Santander, cuyo dueño era el reconocido negociante Antonio Castro Wilches, ubicada en el vecino municipio de Suratá, que usaba maquinaria producida por Nordyke \& Marmon Co. de Indianápolis, que le permitía una producción diaria de 750 arrobas (Libro Azul de Colombia, 1918, p. 596).

Como las batallas más violentas se sucedieron en Santander, esto afectó la mano de obra y los cultivos, situación que fue aprovechada por el departamento de Caldas para tomar el liderazgo no solo en el cultivo, sino en el uso de tecnología para la producción y comercialización del café. Las guerras civiles del siglo XIX, impulsadas por las contiendas entre conservadores y liberales, centralistas y federalistas, campesinos y hacendados, fueron inducidas por debates políticos agresivos iniciados en las regiones que se volvieron conflicto nacional (Uribe, 2001, p. 19). Por consiguiente, las guerras civiles del siglo XIX convocaron a diferentes estratos sociales y a personas de distinta condición económica, pues los sectores populares vieron en las contiendas la posibilidad de conseguir tierras y riqueza (Uribe, 2001, p. 26). Sin embargo, estas guerras civiles llevaron a que la región santandereana fuese reconocida en la nación por batallas como la de Palonegro o la de Peralonso, confrontaciones que dejaron a sus habitantes al margen del desarrollo, el 
progreso y la industrialización. Uno de los sectores en que se puede apreciar el impacto de las guerras civiles y el uso de tecnología fue en el cultivo del café. En Bucaramanga, solo los ingenieros Hakspiel y Penagos tenían talleres especializados en metalmecánica y no se sabe hasta qué punto los cultivadores de café recurrieron a sus servicios profesionales, y si el uso de las herramientas que fabricaban fue generalizado o se limitó a unas haciendas. Teniendo en cuenta lo anterior, la tecnología fue otra de las claves para que el proceso de industrialización en Antioquia, Bogotá y Valle del Cauca fuera más desarrollado que en Santander. Echavarría resalta el liderazgo industrial de dichas regiones, mientras que se refiere a Boyacá, Santander y Nariño como regiones con fuerte presencia artesanal y sin ninguna preponderancia nacional (Echavarría, 1999, pp. 51, 104-105).

\section{SECTORES DE INVERSIÓN, NE- GOCIANTES Y EMPRESARIOS}

Tópicos como el proceso de industrialización remiten al concepto de industria, el cual ha sido objeto de numerosas definiciones que apuntan al predominio de la máquina o tecnología sobre la mano del hombre. En este universo conceptual, Luis Jáuregui, con base en la experiencia mexicana, pionera en América Latina, la define como "un conjunto de operaciones que concurren a la transformación de las materias primas y la producción de riqueza, independientemente de la tecnología" (Romero, 2016, p. 17). Además, el autor aclara que en esta definición se habla de transformación que involucra tecnología, pero no de una tecnología específica, lo cual hace que el vocablo sea atemporal y se pueda usar para identificar transformaciones de cualquier índole sin caer en lo anacrónico. Es así como en las fuentes consultadas se pueden leer las siguientes acepciones: industria del contrabando, del petróleo, del café, del fique, de la seda, del tabaco, pecuaria, minera, hotelera, ganadera, del dulce, del carbón mineral, de la madera, y cuando el socio hacía su aporte en trabajo también se le llamaba industria (ANPB, 1906). Por consiguiente, la industrialización sería el proceso mediante el cual el Estado o el sector privado fomentan el paso de talleres a unidades económicas tecnificadas como fábricas e industrias que motivan el desarrollo económico.

En Colombia, los principales centros urbanos empezaron a ser atractivos para la población campesina, teniendo en cuenta el número, la calidad de los empleos y los salarios. Este proceso migratorio afectó

el crecimiento de la población y la educación en la medida en que las personas con cierto nivel educativo podían acceder a mejores oportunidades de empleo en la ciudad, no solo por la mayor demanda de empleos calificados sino también porque los retornos a la educación eran mayores en las zonas urbanas que en el campo. (Berdugo, 2019, p. 174)

como fue el caso de Medellín. 
En este orden de ideas, el proceso de industrialización ha tenido y tendrá manifestaciones específicas por países y regiones (Romero, 2016, p. 137), y para tratar de entenderlo, la historia económica ha tomado el modelo de Gunnar Myrdal y Albert O. Hirschman. Según estos autores, para el proceso de desarrollo capitalista se parte de la fase de la acumulación primigenia hasta llegar a la fase actual marcada por una internacionalización cada vez más fuerte del capital y, por consiguiente, a un modo de producción capitalista en la periferia (Courlet, 1983, p. 72). Dicho proceso es más acertado que la teoría etapista propuesta por Rostow y Gerschenkron y enfoca el sistema productivo como un fenómeno mundial mediante la creación de industrias, las transferencias de tecnología y las migraciones de mano de obra (Courlet, 1983, p. 72). Con base en este planteamiento, el proceso de industrialización en Bucaramanga estaba en una etapa elemental, teniendo en cuenta que había pocas fábricas y no todas contaban con una tecnología compleja, prevalecían los talleres y fabriquines, con una pequeña acumulación de capitales, algún interés de exportar e importar productos, con predominio de la manufactura y un desarrollo tecnológico débil.

Por otra parte, una revisión del proceso de industrialización en la ciudad lleva a la conclusión de que la mayoría de las inversiones en sociedades comerciales fueron orientadas hacia la producción de cigarros, cigarrillos, velas y fósforos; banca y finanzas, construcción, almacenes de importación y exportación, comunicaciones telefónicas, terrestres, fluviales y aéreas; bebidas y alimentos, farmacias y boticas, vestuario y calzado, talleres de carpintería, talabartería, latonería, joyería, platería y entretenimiento, siendo el de cigarros y cigarrillos el de mayor concentración.

En primera instancia, el cultivo de tabaco en Bucaramanga, Girón y Piedecuesta tuvo su trasfondo en la época colonial, al igual que la elaboración de cigarros; los aranceles y la comercialización fueron un tema de discusión durante el siglo XIX hasta que en 1892 se determinó que "la venta y fabricación de cigarrillos era un monopolio del Estado" (Ocampo, 1984, p. 176). Posteriormente, el monopolio le fue entregado a los particulares, lo cual condujo al aprovechamiento a gran escala. Este sector gozó de bastante inserción de tecnología, generó empleo, especialmente femenino, y produjo excedentes para exportar a los departamentos de Antioquia, Atlántico, Bolívar, Boyacá, Caldas, Cauca, Cesar, Cundinamarca, Magdalena, Norte de Santander, Tolima, Valle del Cauca y San Andrés y Providencia, así como a Venezuela y otros países que las fuentes no especifican.

Para corroborar lo anterior, se pueden citar dos de las fábricas más grandes en Bucaramanga. Una fue La Hamburguesa, que en 1919 producía entre 55000 y 60000 cigarros diarios con un promedio de 1800000 mensuales, 
de los cuales 300000 se vendían en Santander y 1500000 se exportaban a otros departamentos. La segunda fue La Playa, que en 1916 elaboraba diariamente un millón de cigarros y cigarrillos para el mercado local y los excedentes se exportaban a Bogotá, Medellín y Barranquilla. Con referencia al número de obreros que trabajaban en este sector, en 1928 se afirmaba que se generaban 15000 empleos, de los cuales 5000 eran ocupados por mujeres (La Vanguardia Liberal, 1928, p. 1).

Entre las fábricas de cigarros y cigarrillos más grandes y con innovaciones tecnológicas estaban La Hamburguesa, El Buen Tono de Emilio Garnica, La Habanera de Villamizar Hermanos, La Playa de Alarcón Hermanos, La Imperial de Felipe Barco, Colombia de David Puyana, Hno. \& Cía., La Constancia de Francisco García Cadena y La Estrella de Alfonso Alviar. Otras no tan destacadas fueron El Sol de Trillos \& Cía., El Beso, La Legitimidad de Botero \& Olarte, La Sirena de Antonio Peralta y Cigalia de Ruíz \& Co.

Un complemento al renglón anterior fue la producción de fósforos y velas, que no se destacó en la región y cuya demanda se cubría con la producción antioqueña de la marca Olano y otras como El Cóndor, Tequendama y Media Luna. En 1927 se abrió El Vulcano, que luego fue vendida a la Compañía Fosforera de Colombia, con casa matriz en Manizales; otras fueron El Gallo y Pielroja de los hermanos Rodríguez Alarcón. En el sector de las velas, la única fábrica referenciada fue La Economía de Chedraui \& Korgi, que se fusionó con La Libertad en 1926.

Con referencia a las bebidas y alimentos, hubo producción de harinas, pastas, chocolate, café molido, cervezas, aguas gaseosas y licores, que era la tendencia en América Latina y que puso a la ciudad a la par con el desarrollo que se vivía en el continente. Esta producción fue motivada por el Estado y tenía como objetivo la sustitución de importaciones, mejorar la calidad de vida y recolectar nuevos impuestos. Con relación a las harinas, la primera fábrica fue La Imperial, de propiedad de Antonio Castro Wilches, la cual estaba ubicada en el vecino municipio de Suratá; su localización obedeció a la alta producción de trigo en la región, además su cercanía a Bucaramanga facilitaba la comercialización; esta materia prima era usada para elaborar pan, arepas y pastas en las fábricas de macarrones y fideos como La Italiana de Gavassa e Hijo y La Colombiana de Barreto Hermanos.

Con respecto a los chocolates, el cacao provenía de Girón y San Vicente de Chucurí, en el departamento de Santander. La primera fábrica reseñada en el diario local fue Chocolate Santander de Elvira Gómez de Moreno; en 1927 se promocionaban las marcas Pielroja y San Bernardo de la Compañía Nacional de Chocolates de la sucursal de Bucaramanga, y en 1929 Chocolate Pinto de las Empresas Unidas Hipinto y Chocolate 
Tres Estrellas de la fábrica La Constancia de Víctor Martínez Villalba. Como los patrones de consumo cambiaron, la costumbre de tostar y moler café en la casa, que fue una actividad habitual desde la época colonial, pasó a manos de Pinto \& Hermano que elaboraban el Café Pinto, y Luis Alfredo Cadena que promocionaba la marca La Industrial en 1922.

En cuanto a las bebidas, una de las más populares fue la cerveza, que se empezó a producir en La Esperanza (ANPB, 1917) ${ }^{8}$, del danés Christian Clausen, la cual inició labores antes que Bavaria (1890) del alemán Leo S. Koop. Esta factoría se caracterizó por la constante innovación tecnológica que le permitió ofrecer variedad de productos y poco a poco cambiar el consumo de chicha y guarapo al de cerveza, que era una de las intenciones del Estado; otra cervecería fue El Cóndor, que usaba malta en la fabricación de los productos. En este mercado, una novedad durante los años veinte fueron las "aguas gaseosas", cuya oferta estuvo a cargo de las fábricas Estrella Clausen (1924) de Christian Clausen, Hipinto, de Hipólito Pinto y la Posada Tobón de origen antioqueño, las cuales monopolizaron la producción de bebidas en la región.

El vestuario y el calzado fue otro sector empleado en la sustitución de importaciones, también fue un medio de sustento familiar y tuvo un rol diferenciador por género, es decir, los hombres se dedicaban a la sastrería, sombrerería y calzado, y las mujeres a la modistería y la confección de ropa interior masculina y femenina. Para la elaboración se empleaban telas de las fábricas de San José de Suaita, localizada al sur del departamento de Santander, o las de Samacá en Boyacá, pero las preferidas por su calidad, variedad y diseños eran las de la fábrica antioqueña $\mathrm{El}$ Hato, que fueron distribuidas en la ciudad desde 1931 por Estanislao Olarte. Como complemento al vestuario estaba la producción de botones de tagua a cargo de las Hermanas Hakspiel, que empleaban maquinaria diseñada por sus hermanos. En cuanto al calzado, las clases pudientes usaban importados o los producidos en algunas zapaterías locales como La Nacional de Manuel Puyana, La Pilonieta y La Orejuela, mientras que los sectores menos favorecidos portaban las tradicionales alpargatas que eran manufacturadas por Martín Parra y Manuel Hernández. Un elemento indispensable en el vestuario fueron los sombreros que eran elaborados y reparados en las sombrererías La Popular de Pedro Otero, La Palma de Rangel \& Co. y La Patria de Manuel A. Ferreira.

Un sector hacia el cual los inversionistas dirigieron sus capitales fue el entretenimiento, especialmente después de los años veinte, cuando la ciudad gozaba de cierta solidez económica y su población había crecido. Así, algunos negociantes

8 Este documento corresponde a la segunda reestructuración de la fábrica. 
consideraron que se necesitaban sitios de esparcimiento y abrieron cafés en el centro de la ciudad como El Royal, La Pola y El Tirol, que no solo ofrecían espacios para la diversión sino diferentes tipos de comida. Uno que se mantuvo vigente durante varias décadas fue el Café Inglés, que ofertaba el servicio de recepciones y cenas para toda la familia. Dentro de la industria cultural estuvo el cine, que para la época empezó a formar parte de la cotidianidad de las grandes urbes y Bucaramanga no se quedó atrás; por consiguiente, algunos negociantes organizaron el Teatro Peralta (1893) de Anselmo Peralta, el Teatro-Circo Garnica (1923) de Emilio Garnica, que ofrecía películas divididas en partes como era la costumbre de la época, corridas de toros y espectáculos de talla nacional e internacional, y el Teatro Santander. Otro espacio que está presente en la memoria colectiva porque era al aire libre, tenía un lago artificial y ambiente familiar fue el Luna Park, ubicado al oriente de la ciudad, pero por los resultados obtenidos tuvo una vida corta. Finalmente, en 1930 se abrió el Club Campestre (ANPB, 1930), que fue concebido como el espacio de relación social de la élite bumanguesa y en el que participaron negociantes como Antonio Chedraui, Alfonso Silva Silva y Christian Clausen, entre otros.

De acuerdo con el número de sociedades mercantiles en las que participaron, el monto de los capitales, su prestancia social, su apoyo en la planeación de la ciudad y su participación en la política, los negociantes de las tres primeras décadas del siglo XX en Bucaramanga se pueden agrupar en mayores y menores. Entre los primeros se encuentran Reyes González, Tobías Valenzuela, David Puyana Figueroa, Emilio Garnica, Antonio Castro Wilches, Alfonso Silva Silva, Villamizar Hermanos, Hipólito Pinto Herrera, Hakspiel Hermanos, Quintilio Gavassa Mibelli, Víctor Alarcón, Christian Peter Clausen, Mariano y Eugenio Penagos, Chedraui Hermanos y Víctor Manuel Ogliastri. En la segunda clasificación se destacaron Barbour Hermanos, Alfredo Cadena D'Costa, Isaías Cepeda, Chalela Hermanos, Alfredo García Cadena, Ismael Gómez Plata, José Domingo Jácome Niz, Lega Hermanos, Víctor F. Paillié, Luna Hermanos, Parra Hermanos, Alfredo \& Ambrosio Peña, Eliseo Serrano, Clímaco Silva Silva, Lázaro Foción Soto y Henry Stunkel.

Dentro de este panorama económico hubo algunos negociantes que se transformaron en "empresarios" o alguien que "se encarna en un agente con determinadas características para crear e innovar, también para adoptar las decisiones necesarias que permitan acometer con éxito nuevos proyectos o negocios y saber asumir los riesgos que se encuentran en este diseño particular" (Primo \& Turizo,2016 , p. 17). Por consiguiente, el empresario responde a las oportunidades, avizora el riesgo y lo maneja, posee la capacidad para llegar a acuerdos y evitar conflictos y, lo más importante, está a la vanguardia 
en cuanto a la innovación tecnológica y administrativa, permitiéndole posicionarse y consolidar su empresa.

En Bucaramanga se pueden citar a Villamizar Hermanos, quienes poseían una de las fábricas de cigarrillos más grandes, la cual tuvo su origen en un fabriquín en el año de 1900 y en 1921 empleaba 200 trabajadores (ANPB, s.f.); en 1927 contaba con 350 y mensualmente producía 1500000 cigarros finos y 350000 paquetes de cigarrillos, los cuales se vendían en el país y en el exterior. Otras de sus inversiones se dirigieron a la empresa de transportes terrestres, la empresa de buses y la empresa de construcciones; de estas asociaciones, la de cigarros y cigarrillos sobrevivió a la crisis de 1929 y en 1941 aún funcionaba.

También se puede mencionar a Hipólito Pinto Herrera, quien empezó sus incursiones en 1914 con una tostadora de café, cacao y maíz, que derivó en la elaboración del Chocolate Pinto; posteriormente vendió café y maíz molido de su propia marca y en 1934 tenía graneros para el secado del arroz. En 1922, y en asocio con Eleuterio González, organizó Pinto \& Cía. para producir cerveza, pero como en ese año el socio falleció, la fábrica quedó en manos del señor Pinto, quien empezó a producir "aguas gaseosas" de las referencias Kola y Soda Hipinto. En 1928 producía velas "Chapiadas" y el jabón para lavar ropa marca "Lava bien". Hacia 1936 incursionó en los materiales para la construcción con el "Barniz Aleados N. 3” y, finalmente, en 1943 empezó a producir harinas deshidratadas, todo bajo el lema Empresas Unidas Hipinto.

Finalmente, la crisis económica mundial de 1929 afectó económicamente la ciudad entre 1932 y 1934, la cual se observó en la parálisis de los negocios, especialmente en el comercio internacional, porque la impuntualidad de los pagos afectó las obligaciones con los bancos locales. Ante esta situación, a reconocidos negociantes se les abrieron procesos judiciales ${ }^{9}$, algunas sociedades sobrevivieron a la crisis, pero no con el apogeo de los años veinte, algunos de los fundadores tenían una edad avanzada y otros murieron, y como no había un tejido familiar o empresarial, sus descendientes liquidaron las sociedades comerciales. Se desconoce si participaron en otras inversiones en la ciudad o el país.

\section{CONCLUSIONES}

En Bucaramanga, durante 1902-1929 hubo predominio de la manufactura debido a factores como el monto de los capitales y la estrechez de los mercados locales y nacional, que frenaron la organización de grandes proyectos empresariales, que es uno de los rasgos de la estructura empresarial tradicional. En otras sociedades como la mexicana,

9 Se abrieron procesos ejecutivos a Gustavo Cáceres, Eugenio Penagos, Miguel Chedraui, Miguel L. Safi y Roberto Gómez Plata, entre otros, y la entidad más afectada fue el Banco Comercial Antioqueño. 
el industrial no tuvo como centro la manufactura, sino la producción de bienes de consumo básico e intermedio. Otra característica fue que paradójicamente sí hubo asociación en la región y se evidencia en la organización de las sociedades comerciales, la interpretación que se puede hacer es que no hubo asociación entre empresas similares para conformar una unidad económica de grandes alcances. Otra situación que influyó en el lento avance de la industrialización fue la ausencia de instituciones de educación superior que formaran profesionales para generar desarrollo económico, pues solo desde 1948 la ciudad contó con la Universidad Industrial de Santander, cuyo objetivo era la industrialización de la región, y mientras esto sucedía, otras regiones ya habían formado profesionales en todas las áreas desde hacía medio siglo o más.

La sustitución de importaciones como política estatal después de los años treinta buscaba la producción y el consumo de los productos nacionales, pero investigadores como Ocampo (1984) afirman que se inició en la segunda década. Después de la crisis del 29 se acentuó y se manejó mediante la "fuerza espiritual emocional", es decir, se acudió a sentimientos nacionalistas y se presentó la industria como generadora de "bienestar nacional" (Romero, 2016, p. 138); en el país se condujo bajo el lema "Todo por Colombia y solamente para Colombia", que se reforzaba desde la prensa local mediante el Decálogo
Económico del Colombiano (Periódico El Deber, 1930, p. 4).

Una estrategia del Estado para motivar la industrialización fueron las semanas y exposiciones industriales, en las que negociantes, empresarios, industriales y público en general promocionaban sus productos provenientes del sector manufacturero, y no del fabril, empresarial o industrial; en Bucaramanga, la Primera Semana Industrial se desarrolló en 1931 con la participación de 142 expositores (Vanguardia Liberal, 1931, pp. 4-6), pero se desconoce el impacto de estas actividades en el desarrollo económico.

A pesar de los esfuerzos gubernamentales en el nivel local para fomentar la economía bumanguesa a través de la industrialización, esta no se ha consolidado en la región. Si bien para los años 50 y 70 del siglo XX existían reconocidas empresas en el sector de la construcción y las confecciones, la falta de una sucesión gerencial llevaría al cierre de factorías y fábricas, las cuales, dicho sea de paso, estaban atrasadas en el impulso tecnológico comparadas con empresas de los departamentos de Antioquia y Valle del Cauca, los que actualmente cuentan con procesos de industrialización avanzados, al menos si se les confronta con la región santandereana, pues también están lejos de una modernización como la de los países del primer mundo. 


\section{AGRADECIMIENTOS}

El artículo es resultado de la investigación "Prensa y política en Santander: ideología, violencia y accionar partidis- ta, 1930-1946", la cual ha sido financiada por la entidad pública Vicerrectoría de Investigación y Extensión de la Universidad Industrial de Santander.

\section{REFERENCIAS}

Acevedo, A. \& Torres, J. (2016). La renta de tabaco en la Nueva Granada: administración, comercio y monopolio. Revista Sociedad y Economía, (30), 281-303.

Archivo Notaría Primera de Bucaramanga (ANPB). (1872). Tomo III, caja 84, instr. n. ${ }^{\circ}$ 550, ff. 422-446.

Archivo Notaría Primera de Bucaramanga (ANPB). (1884). Tomo IV, caja 139, Instr. n. 514 , f. $1393 \mathrm{v}$.

Archivo Notaría Primera de Bucaramanga (ANPB). (1906). Tomo VII, instr. n. 1307 , ff. 3007-3009.

Archivo Notaría Primera de Bucaramanga (ANPB). (1914). Tomo V, instr. n. ${ }^{\circ}$ 1166, ff. 3152-3167.

Archivo Notaría Primera de Bucaramanga (ANPB). (1915). ANPB. Tomo II, instr. n. ${ }^{\circ} 456$, ff. 1125-1129.

Archivo Notaría Primera de Bucaramanga (ANPB). (1917). ANPB. Tomo IV, instr. n. ${ }^{\circ} 847$, ff. 1988-1993.

Archivo Notaría Primera de Bucaramanga (ANPB). (1930). ANPB. Tomo III, instr. n. ${ }^{\circ} 508$.

Archivo Notaría Primera de Bucaramanga (ANPB). (s.f.). ANPB. Tomo IV, instr. n. ${ }^{\circ}$ 713, ff. $2310-2312$.

Archivo Notaría Segunda de Bucaramanga (ANSB). (1880-1929).

Arroyo, J. (2006). Historia de las prácticas empresariales en el Valle del Cauca. Cali: Universidad del Valle. 
Berdugo, E. (2019). La industrialización en Bogotá entre 1830 y 1930. Un proceso lento y difícil. Bogotá: Utadeo.

Carreño, C. (2015). Puertos locales y bienes de consumo e importación de mercancías finas en Santander, Colombia 1870-1900. América Latina en la Historia Económica, 22 (1), 85-114. https://doi.org/10.18232/alhe. v22i1.600

Censo del Estado Soberano de Santander. (1871).

Censo de Población del Departamento de Santander. (1896).

Correa, J. (2011). El ferrocarril de Panamá y la pérdida de una nación. Revista Credencial Historia, (315), 52-59.

Courlet, C. (1983). El análisis de la industrialización periférica o la historia de una doble encrucijada. Revista Lecturas de Economía, (11), 69-83.

Cruz, A. (1964). La administración Reyes. Boletín Cultural y Bibliográfico, (10), 201-243.

Dávila, C. (1986). El empresariado colombiano: una perspectiva histórica. Bogotá: Crear Arte.

Echavarría, J. (1999). Crisis e industrialización. Las lecciones de los treintas. Bogotá: Tercer Mundo.

Espinosa, C. (2017). El Banco Santander. Revista Estudio, (343), 96-97.

Galán, M. (1947). Geografía económica de Colombia. Tomo VIII-Santander. Bucaramanga: Contraloría General de la República.

Giraldo, J., Fortou, J. \& Gómez, M. (2019). 200 años de guerra y paz en Colombia: números y rasgos estilizados. Co-Herencia, (31), 357-371. https://doi.org/10.17230/co-herencia.16.31.11

Guerrero, A., Acevedo, A. \& Fuentes H. (2014). Santander. Territorio, cultura y política. Visión prospectiva 2019/2030. Bucaramanga: Publicaciones UIS. 
Guerrero, A. \& Avellaneda, M. (2003). La élite empresarial en Santander 1880-1912. En Cepal (ed.), Empresas y empresarios en la historia de Colombia. Siglos XIX y XX (pp. 141-178). Bogotá: Norma.

Johnson, D.C. (1989). Reyes González Hermanos: la formación del capital durante la regeneración en Colombia. Boletín Cultural y Bibliográfico, (23), 25-43.

Laurent, M. (2008). Contrabando en el siglo XIX. Prácticas y discursos de resistencia y reproducción. Bogotá: Universidad de Los Andes.

Libro Azul de Colombia. (1918). New York: The J.J. Little \& Yves Company.

Martínez, A. (2005). Bartolomé Rugeles. Diarios de un comerciante bumangués 1899-1938. Bogotá: Guadalupe.

Martínez, A. (2013). 122 años de luz y fuerza en Santander. Bucaramanga: Electrificadora de Santander.

Meisel, A. (2015). Antecedentes del Banco de la República 1904-1922. Cuadernos de Historia Empresarial y Económica, (37), 1-26.

Molina, L. (2006). Empresarios colombianos del siglo XIX. Bogotá: Norma-Uniandes.

Ocampo, J. (1984). Colombia y la economía mundial 1830-1910. Bogotá: Siglo XXI.

Olarte, A. (2006). La construcción del ferrocarril de Puerto Wilches a Bucaramanga 1870-1941. Sintesis de una obra discontinua y costosa. Bucaramanga: Sistemas y Computadores.

Periódico El Deber. (1930). N. ํㅜㄹ 2077, p. 4.

Periódico El Deber. (1931, 2 de abril), p. 2.

Periódico El Posta. (1893). N. ${ }^{\circ}$ 5, p. 3. Bucaramanga.

Periódico El Posta. (1895). N. ${ }^{\circ}$ 50, p. 7 Bucaramanga.

Periódico Vanguardia Liberal. (1928). N. ${ }^{\circ}$ 2716, p. 1. Bucaramanga.

Periódico Vanguardia Liberal. (1929). N. 2976, p. 5. Bucaramanga.

Periódico Vanguardia Liberal. (1931). N. 3748, pp. 4-6. Bucaramanga. 
Pradilla, O. (2012). El ferrocarril de Cúcuta 1876-1960: expresión de unos cambios regionales. (Tesis de maestría). Pontificia Universidad Javeriana, Bogotá.

Primo, W. \& Turizo, H. (2016). Emprendedor y empresario: una construcción desde la dinámica del pensamiento económico. Inquietud Empresarial, 16(1), 13-52.

Rippol, M. (1997). Los inicios de la industrialización en el Caribe colombiano. Boletín Cultural y Bibliográfico, (34), 59-92.

Rodríguez, H. (1968). La inmigración alemana al Estado Soberano de Santander. Bogotá: Kelly.

Romero, M. (2016). La industria mexicana y su historia. Siglos XVIII, XIX y XX. México: UNAM.

Sáenz, E. (2007). La ofensiva empresarial: industriales, políticos y violencia en los años 40 en Colombia. Bogotá: Tercer Mundo Editores.

Uribe, M. (2001). Las guerras por la nación en Colombia durante el siglo XIX. Estudios Políticos, (18), 9-27.

Valdivieso, S. (1991). Historias de setenta y cinco años. Bucaramanga: Cámara de Comercio. 